\title{
The National Asthma Education Programme and asthma in Africa
}

The National Asthma Education Programme (NAEP) is a registered non-profit organisation whose mission is to provide asthma education to healthcare professionals, patients and the lay public. It was founded in 1994 by Dr Mike Greenblatt and Profs Dave Luyt and Robin Green. This year NAEP celebrates its 25th anniversary and remains driven by the need to improve the daily lives of numerous asthmatics in South Africa (SA) and Africa.

Africa comprises 54 countries and 1.2 billion people with huge differences in multiple aspects of asthma - from prevalence to access to medical care. There are many dedicated home-grown researchers who have laid the foundation for a good understanding of asthma in Africa, and numerous articles have been published describing every aspect of asthma on the continent.

What is the asthma prevalence and its reported increase in Africa over the past few decades? Probably the most comprehensive report is from the International Study of Asthma and Allergies in Children (ISAAC) that consists of three phases. Phase I, which took place between 1991 and 1996 in 155 centres in 38 countries, used simple standardised questionnaires to assess the prevalence and severity of asthma and allergic disease in children between 6 and 7 ( $n=257$ 800) and 13 and $14(n=463801)$ years of age. ${ }^{[1]}$ The prevalence of childhood asthma varies throughout the world, with the highest prevalence in the 12 months preceding ISAAC phase I being in Australia and New Zealand (29.7\%) and the lowest in Asia (6.6\%). The African centres involved in ISAAC phase I were in Ethiopia, Kenya, Nigeria, Algeria and SA. ISAAC phase III was conducted 5 - 7 years later, using the same methodology. ${ }^{[2]}$ The goal was to review the trends of asthma prevalence over the preceding years and to investigate the influence of potential environmental factors. Whereas there had been 6 African centres involved in phase I, phase III involved 22 centres from 16 African countries. The prevalence of asthma in Africa had increased by $0.10 \%$ per year in the $6-7$-year group and $0.16 \%$ per year in the 13 - 14-year group. In Cape Town, the following had all increased significantly in the 13 - 14-year group between phase I and phase III: 12 -month prevalence of wheezing (16\% v. $20.3 \%)$, exercise-induced wheezing $(21.5 \%$ v. $32.5 \%)$, nocturnal cough $(23.6 \%$ v. $36.6 \%)$, sleep disturbance due to wheezing $(9.6 \%$ v. $16 \%)$ and severe wheezing $(5.1 \%$ v. $7.8 \%))^{[3]}$

ISAAC and other studies found that there is a pronounced difference between asthma prevalence in rural and urban areas in Africa. There was something 'asthmagenic about living in African cities' and 'fitting an explanation to the pattern is fraught with difficulty and tends to end in vague generalizations about "westernisation", a catchall phrase which covers a host of theories. ${ }^{[4]}$ This implies a shift in balance between rural and urban environments, where children are exposed from early infancy to a varying range of foods, infections, parasites, indoor and outdoor allergens and irritants such as motor vehicle and biomass pollution and pesticides. Therefore, it must be understood that the massive population shifts from rural to urban communities lead to further increases in the number of asthmatics in Africa and that a huge strain will be placed on already burdened health systems with limited resources.

Of more concern than the increase in prevalence is that, despite African countries not ranking poorly on prevalence rates, their asthma mortality rates are unacceptably high. The Global Initiative for Asthma (GINA) Dissemination Committee report shows that the overall prevalence of asthma in all age groups is: SA $-8.1 \%$, Ivory Coast $-7.8 \%$, Kenya $-7.0 \%$ and Nigeria $-5.4 \%$. However, in SA, the case fatality rate for asthmatics was reported as 18.5 per 100000 asthmatics, the fifth highest in the world. ${ }^{[5]}$ Therefore, whereas the prevalence of asthma in countries such as Australia, New Zealand, the UK and the USA may be much higher than in Africa, their case fatality rate is much lower, with Australia, New Zealand, the UK and the USA reporting fatality rates of between 3.2 and 5.2 cases per 100000 asthmatics.

What causes these disappointing numbers? Although financial and infrastructural problems are well documented, there is also often a lack of knowledge about asthma, including its severity classification and general management principles.

Therefore, what can be done? SA has excellent asthma guidelines that are regularly updated and locally published (https://pulmonology. co.za/guidelines-recommendations/). There are also international guidelines such as those disseminated through GINA (https:// ginasthma.org/), asthma awareness campaigns and world asthma day (yearly on the first Tuesday in May).

NAEP has provided asthma education for the last 25 years. Its mission is to improve asthma management and to promote the goals of asthma management, including the complete clinical control of asthma in most people who have the condition. This is achieved through education of healthcare professionals and by providing credible, unbiased, peer-reviewed asthma information to patients and the public. The objectives of NAEP are to raise awareness about asthma management among healthcare professionals, patients and the public, ensuring that its symptoms are recognised, medical assistance is sought as early as possible and the concept of complete clinical control of asthma is promoted.

This goal has been achieved by the dedication of the past chairpersons and their teams, generous support from the pharmaceutical industry and support on multiple levels to the healthcare community and the public. Our benchmark asthma education course is the only accredited asthma course in SA, and asthma educator certificates have been provided to $>700$ individuals across SA since 2000. Asthma education pamphlets are widely distributed throughout SA and are freely available (http:// www.asthmasa.org). The very successful asthma medication poster was updated in 2018. A yearly world asthma day campaign through multiple social media platforms, radio and television interviews (https://www. facebook.com/NAEPSA/) is also run. NAEP social media platforms have grown exponentially over the past few years, enabling many more people to learn about the condition.

To commemorate our 25th anniversary, we decided to expand our footprint across SA and the African continent. The number of asthma topics that our pamphlets cover will be increased and translated into the 11 official languages of SA. It is hoped that this service will include more African languages in the future. To widen our footprint and improve the quality of life of all those with asthma on the African continent, we will also start the transition from the current asthma course that has been offered for 25 years to a fully online asthma course available throughout Africa. We hope to improve the plight of all who suffer from asthma in our country and on our continent and to continue training those who would like to make a difference in the lives of asthmatics.

\section{Charl Verwey}

NAEP chairperson

Division of Paediatric Pulmonology, Department of Paediatrics,

Chris Hani Baragwanath Academic Hospital, Faculty of Health

Sciences, University of the Witwatersrand, Johannesburg, South Africa charl.verwey@wits.ac.za 
1. Strachan D, Sibbald B, Weiland S, et al. Worldwide variations in prevalence of symptoms of allergic rhinoconjunctivitis in children: The International Study of Asthma and Allergies in Childhood (ISAAC) Pediatr Allergy Immunol 1997;8(4):161-176. https://doi.org/10.1016/S0091-6749(99)70536-1

2. Pearce N, Ait-Khaled N, Beasley R, et al. Worldwide trends in the prevalence of asthma symptoms: Phase III of the International Study of Asthma and Allergies in Childhood (ISAAC). Thorax 2007;62(9):758-766. https://doi.org/10.1136/thx.2006.070169

3. Zar HJ, Ehrlich RI, Workman L, Weinberg EG. The changing prevalence of asthma, allergic rhinitis and atopic eczema in African adolescents from 1995 to 2002. Pediatr Allergy Immunol 2007;8(7):560-565. https://doi.org/10.1111/j.1399-3038.2007.00554.
4. Cullinan P. Asthma in African cities. Thorax 1998;53(11):909-910. https://doi.org/10.1136/thx.53.11.909 5. Masoli M, Fabian D, Holt S, Beasley R. The global burden of asthma: Executive summary of the GINA Dissemination Committee report. Allergy 2004;59(5):469-478. https://doi.org/10.1111/j.13989995.2004.00526.x

S Afr Med J 2019;109(7):453-454. DOI:10.7196/SAMJ.2019.v109i7.14090 